\title{
Escuela pública y maestro en América Latina. Historias de un acontecimiento, Siglos XVIII-XIX
}

Autores: Alberto Martínez Boom y José Bustamante Vismara (Compiladores)

Editorial: Prometeo, Buenos Aires, Argentina

Año de publicación: 2015

Número de páginas: 342

ISBN: 978-987-574- 660-2

En el marco de las nuevas perspectivas de investigación que buscan ampliar el campo de estudio de la historia de la educación más allá de la configuración estatal moderna, este libro plantea la aparición de la escuela a finales del siglo XVIII como la irrupción de un acontecimiento que reordenó formas y prácticas. En este sentido, los artículos aquí compilados dan cuenta de cómo el Estado contribuyó a la formación de la escuela, pero también que ésta al mismo tiempo fue un punto nodal en la aparición del Estado, que resultó en una escuela diferencial y unificada con la que se iniciaron los procesos de escolarización en los territorios latinoamericanos. Un aporte clave a esta nueva mirada sobre la cuestión educativa, es que este libro reconoce en la figura del maestro a un personaje central del proceso de organización escolar, en cuyo cuerpo se inscriben las instituciones escolares; no obstante, el maestro aparece como objeto público intervenido por el Estado, que no deja de tener una posición marginal, ¿por qué?, ¿qué relación hay entre maestros, escuela y Estado? El desarrollo de la escolarización en tanto hecho político incuestionable dado su valor en términos de gobierno de la conducta de las poblaciones, es en principio la respuesta.

En términos teóricos, este libro retoma la tesis de Ian Hunter según la cual la escuela moderna nace como una combinación aleatoria de dos lógicas diferentes de relaciones de saber-poder. Por un lado, la lógica de la organización, operada desde la autoridad burocrática y desde el creciente interés estatal por las prácticas ocultas de la escolaridad; y por el otro, la lógica del pastorado de la relación saber-poder planteada por M. Foucault. En esta clave, Martínez Boom y Bustamante Vismara, presentan una serie de artículos y análisis historiográficos que reactualizan los interrogantes sobre la constitución de la escolaridad en América Latina y la envergadura del proceso histórico que representa la transición entre los siglos XVIII y XIX. No obstante, el análisis aquí planteado se enriquece por la valoración de los procesos regionales en América Latina, con el objetivo de des-estatalizar la cronología histórico educativa vinculada al estudio de los sistemas educativos modernos.

Historiográficamente, el conjunto de artículos aquí reunidos trabaja con la acumulación de series documentales, de intentos de totalidad y de narraciones diferenciadas y localizadas que construyen un relato histórico no meramente genealógico o arqueológico para este tipo de análisis, proponiendo al investigador poner el foco más en los hechos y su contundencia, que en las miradas macro que intentan explicar la historia de la educación en términos de Nación. Metodológicamente el libro es una crítica a la historia comparada que se pretendía bisagra de la lógica monolítica de los estados y las consecuentes miradas nacionalistas, 
aquí la comparación es planteada como forma de romper la supuesta homogeneidad del mundo contemporáneo, y no como la sumatoria de las historias nacionales.

La estructura del libro se compone de dos partes: en la primera presenta un conjunto de ensayos vinculados a cuestiones teórico-metodológicas y de interpretación, ligados estrechamente con problemáticas de una historia no lineal. En este sentido, se reconoce en la historia de las prácticas pedagógicas una especificidad propia cuya periodicidad no coincide necesariamente con los recortes tradicionales de la tarea del historiador. Es la contundencia de los hechos el punto de partida para interrogar todo objeto asumido como dado o evidente. Por ejemplo, se critica el planteo historiográfico sobre "el monopolio de la Iglesia en la educación elemental", considerando que antes de la independencia varias instituciones, además de la Iglesia y los maestros particulares, participaban de la actividad educativa; o en términos conceptuales, se analiza el sentido de lo público para identificar el cambio que representó la intervención del gobierno en un nuevo ámbito de la sociedad a comienzos del siglo XIX. Transformación que se manifestó en plenitud cuando la expresión "fondos de instrucción pública" ya no designaba los bienes de una comunidad concreta, sino que refería a un organismo de gobierno centralizado, cuando comenzó a trasladarse el sentido de lo público asociado al pueblo, al Estado, en el sentido moderno.

La segunda parte presenta un conjunto de estudios históricos que se distinguen por su filiación con la historiografía social de las últimas décadas. En estos ensayos los temas de estudio son el desarrollo de la formación estatal alrededor de las Juntas Protectoras de Escuelas, por ejemplo, para analizar los tipos de relación entre los grupos locales y las autoridades estatales. El sentido de lo público y de la educación pública entre el final del período colonial y la moderna organización estatal, estudios que van dotando a la figura del maestro de mayor centralidad, en tanto actor social en el proceso educativo, y al mismo tiempo analizan esta transición como punto de inflexión de las medidas y acciones que inciden en la construcción de la escuela.

Este libro es una invitación a reflexionar e iniciar líneas de investigación sobre fenómenos comunes a la historia de la educación latinoamericana: los efectos de la expulsión de los jesuitas, la financiación de las escuelas vía fondos particulares, las prescriptivas para la reforma de las costumbres, las medidas para controlar la miseria, la creación de Sociedades Económicas de amigos del país en múltiples lugares de España y América, la circulación y uso de libros, catecismos, cartillas y manuales comunes, en fin todas las prácticas destinadas a conocer y hacer visible una regularidad que necesita ser gobernada: la población, y particularmente, la infancia.

Es un libro muy interesante, que propone una mirada extrañada y poco convencional sobre la diversidad de configuraciones organizadas en torno a la escuela, de prosa amena y ligera, pero de lectura rigurosa.

Antonela Centanni Universidad Nacional de Jujuy (Argentina) 